\title{
Approaches for drug delivery with intracortical probes
}

Sven Spieth ${ }^{1, *}$, Axel Schumacher ${ }^{1}$, Fabian Trenkle ${ }^{2}$, Olivia Brett ${ }^{2}$, Karsten Seidl $^{3}$, Stanislav Herwik ${ }^{3}$, Sebastian Kisban ${ }^{3}$, Patrick Ruther ${ }^{3}$, Oliver Paul ${ }^{3}$, Arno A.A.A. Aarts ${ }^{4}$, Hercules P. Neves ${ }^{4}$, P. Dylan Rich $^{5}$, David E. Theobald ${ }^{5}$, Tahl Holtzman ${ }^{5}$, Jeffrey W. Dalley ${ }^{5,6}$, Bram-Ernst Verhoef ${ }^{7}$, Peter Janssen ${ }^{7}$ and Roland Zengerle ${ }^{1,2}$

${ }^{1}$ Institut für Mikro- und Informationstechnik der Hahn-Schickard-Gesellschaft e.V. (HSG-IMIT), D-78052 Villingen-Schwenningen, Germany

${ }^{2}$ Laboratory for MEMS Applications, Department of Microsystems Engineering (IMTEK), University of Freiburg, D-79110 Freiburg, Germany

${ }^{3}$ Microsystem Materials Laboratory, Department of Microsystems Engineering (IMTEK), University of Freiburg, D-79110 Freiburg, Germany

${ }^{4}$ Interuniversity Microelectronics Center (IMEC), B-3001 Heverlee, Belgium

${ }^{5}$ Department of Psychology, University of Cambridge, Cambridge CB2 3EB, United Kingdom

${ }^{6}$ Department of Psychiatry, University of Cambridge, Cambridge CB2 3EB, United Kingdom

${ }^{7}$ Laboratory for Neuro- and Psychophysiology, Katholieke Universiteit Leuven, B-3000 Leuven, Belgium

\section{*Corresponding author:}

Sven Spieth, Institut für Mikro- und Informationstechnik der Hahn-Schickard-Gesellschaft e.V., Wilhelm-Schickard-Str. 10, D-78052 Villingen-Schwenningen, Germany

Phone: +49-7721-943-241

Fax: +49-7721-943-210

E-mail: sven.spieth@hsg-imit.de 


\section{Abstract}

Intracortical microprobes allow the precise monitoring of electrical and chemical signaling and are widely used in neuroscience. Microelectromechanical system (MEMS) technologies have greatly enhanced the integration of multifunctional probes by facilitating the combination of multiple recording electrodes and drug delivery channels in a single probe. Depending on the neuroscientific application, various assembly strategies are required in addition to the microprobe fabrication itself. This paper summarizes recent advances in the fabrication and assembly of micromachined silicon probes for drug delivery achieved within the EU-funded research project NeuroProbes. The described fabrication process combines a two-wafer silicon bonding process with deep reactive ion etching, wafer grinding, and thin film patterning and offers a maximum in design flexibility. By applying this process, three general microprobe comb designs featuring up to four 8-mm-long shafts, cross sections from $150 \times 200$ to $250 \times 250 \mu \mathrm{m}^{2}$, and different electrode and fluidic channel configurations are realized. Furthermore, we discuss the development and application of different probe assemblies for acute, semi-chronic, and chronic applications, including comb and array assemblies, floating microprobe arrays, as well as the complete drug delivery system NeuroMedicator for small animal research.

\section{Keywords}

silicon microprobes; neural recording; 3D probe arrays; MEMS fabrication; micropump; microfluidics 


\section{Introduction}

One of the fundamental goals of neuroscience is to understand how the central nervous system integrates information and controls behavior by electrical and chemical signaling. Microprobe technology is at the forefront of this research as it enables such activity to be measured on timescales consistent with cognitive processing in the brain, including decision-making and working memory. In this regard, the combination of electrophysiological recording with intracortical drug delivery would provide a powerful tool to investigate neural coding of behavior and cognition.

Typically, pharmacological intervention in neuroscience research employs either microiontophoresis or pressure-driven liquid infusion systems to deliver drugs in the brain $[1,2]$. Today, pressure-driven systems based on stainless steel or glass capillaries are more commonly used as they are independent of the charge states of the drug molecules. In addition, the rapid development of microelectromechanical systems (MEMS) and the associated silicon-based fabrication processes have opened new technological perspectives with respect to functional microprobe integration. Following the pioneering work of Wise et al. [3], a wide variety of micromachined probes has been developed [4]. Depending on the number and geometrical arrangement of the probe shafts, one-dimensional (1D) single-shaft probes, two-dimensional (2D) probe combs with multiple shafts, and fully threedimensional (3D) microprobe arrays can be distinguished.

Given the disc-like shape of silicon wafers, most often in-plane fabrication sequences are applied to realize microprobes with lengths of several millimeters, i.e. probe combs are fabricated in the wafer plane. Considering neural microprobes which combine electrodes and microfluidic channels for electrical recording and drug delivery, respectively, various materials and technological approaches have been pursued. This includes microprobes based on silicon ( $\mathrm{Si}$ ) [5-10], silicon-on-insulator (SOI) [11,12], and polymers such as parylene (Py) [13-15], polyimide (PI) [16,17], and SU-8 [18]. In addition to these main approaches, less common fabrication technologies have also been reported, e.g. a hybrid assembly affixing a silicon microelectrode array to a fused silica capillary [19]. 
Integration of microfluidic channels into the probe body is certainly the most challenging aspect of this kind of probes. Thereby, surface micromachined [13,14], buried [5-7,11,12], and bonded [810,15-18] channels can be generally distinguished. Surface micromachined channels are fabricated by deposition and subsequent etching of thin films and require sacrificial layers during fabrication. Typically, this technological approach results in rather low channel profiles not higher than ten micrometers with widths of a few ten micrometers. Buried channels are predominantly implemented in $\mathrm{Si}$ or SOI substrates. The approach requires first to etch a cavity into the substrate by dry or wet etching methods which is subsequently sealed by the deposition of additional layers such as oxides or polymers. Bonded channels are fabricated by first implementing an open channel structure in or on a substrate. This is followed by bonding of a second structure which seals the open channel, i.e. a structured or unstructured cover. Comparing the three different approaches with respect to the microfluidic design flexibility, the bonding approach is least restricted by the applied fabrication technologies and offers maximum flexibility.

The electrodes on the probes are typically fabricated by patterning of thin films and are made of materials such as platinum (Pt) [7,11,16-18] including Pt-grey [8] and Pt-black [14], gold (Au) $[6,7,10,12,13,15]$, or iridium (Ir) [5].

Depending on the specific neuroscientific application, different microprobe designs are required to reach the relevant areas of the brain. Thereby, the drug delivery functionality has been mostly limited to $1 \mathrm{D}$ or $2 \mathrm{D}$ probes. So far, full 3D arrays with individual micromachined drug delivery shafts have only been addressed by two approaches $[6,20]$. In addition, the micromachined probes have to be integrated into system assemblies offering distinct electrical and fluidic interfaces for the connection of macro-scale electronic and fluidic equipment. This is mandatory in order to be able to operate the microprobes during experiments. In this respect, acute and chronic assemblies have to be distinguished. Whereas acute assemblies are designed for short-term application, typically on a timescale of hours, and are easily fixed to laboratory equipment, chronic assemblies are implanted over longer timescales, typically weeks, and must allow animals the ability to behave in an unconstrained and natural manner. 
Electrical interfacing is commonly effected by taking advantage of the broad range of integrated circuit (IC) packaging technologies. For this purpose, nearly all microprobes feature contact pads predominantly used for wire bonding to printed circuit boards (PCBs) or flexible cables which are in both cases terminated with electrical connectors. Alternatively, connectors can be soldered to the pads [17], reversible contact mechanisms used [18,21], or the pads directly inserted into zero insertion force (ZIF) connectors in case of flexible substrates $[15,16]$. Consequently, electronic equipment can be easily connected and disconnected to the probes. This is especially interesting for all chronic applications. On the other hand, fluidic interfacing requiring the transmission of matter is more complicated. A pluggable microfluidic connection to implanted probes is challenging, possibly introducing contaminations or bubbles into the system. Therefore, drug delivery is currently mostly limited to acute experiments. For this purpose, different kinds of tubing [5,7,11-16] or capillaries [17] are typically irreversibly attached to the probes and connected to macroscopic laboratory pumps. In addition, interfacing with O-rings was addressed [18,21]. So far, few approaches have targeted the integration of active micropumping components into multifunctional microprobes $[10,22]$.

Currently, neuroscientific experiments are predominantly performed with small animals such as rats and mice. In order to enable liquid infusions, different implantable general purpose drug delivery systems such as the iPRECIO $^{\circledR}$ micro infusion pump (Primetech Corporation, Tokyo, Japan) and the ithetis $^{\mathrm{TM}}$ drug delivery device (Antlia SA, Lausanne, Switzerland) are commercially available or are under development [23]. However, these devices are not specifically adapted to micromachined probes and designed for relatively large liquid volumes of up to $1 \mathrm{~mL}$. In general, few miniaturized systems for small animal research specifically addressing intracortical drug delivery by microprobes have been reported so far [24-28]. Whereas early approaches applied either chemitrodes [24] or stainless steel capillaries $[25,26]$ as microprobes, the most recent approaches exploit the extended possibilities of micromachined probes $[27,28]$.

The work described in this paper reviews the drug delivery approaches pursued within the EU-funded NeuroProbes project $[29,30]$ targeting the development of multifunctional 1D, 2D, and 3D neural probe arrays comprising electrodes for electrophysiological recording and stimulation, biosensors, and 
microfluidics. On the basis of a common fabrication process, three basic microprobe designs have been developed. The designs enable different assembly and integration strategies resulting in microprobe comb and array assemblies, floating microprobe arrays, and complete drug delivery systems. Beyond the technical description of the devices, application examples are presented.

All animal related procedures complied with the legal and ethical requirements and local institutional guidelines at the University of Cambridge, United Kingdom, and the Katholieke Universiteit Leuven, Belgium. 


\section{Material and Methods}

\section{Fluidic silicon microprobe concept}

The modular platform approach pursued by NeuroProbes is based on the insertion of individual 2D probe combs into a common platform to obtain a complete 3D array as described in [31-34]. Beyond this, different probe designs offering distinct interfaces for stand-alone assemblies are desirable for versatile applications. In order to address both aspects, a two-wafer bonding process was developed which is compatible with the processes and materials of the modular platform approach pursued by NeuroProbes. In addition, the process offers maximum flexibility in the geometrical probe design as well as the fluidic layout. The applied materials are silicon ( $\mathrm{Si})$ as the probe material and silicon oxide $\left(\mathrm{SiO}_{2}\right)$ as well as nitride $(\mathrm{SiN})$ used as passivation layers. As exemplary illustrated in Figure 1, three basic microprobe designs with various fluidic features have been implemented $[8,20]$ enabling different assembly strategies as described later. Thereby both, in-plane and out-of-plane fluidic supplies as well as outlet ports have been developed. Probe design A (Figure 1A) comprises two slender 8-mm-long shafts with a pitch of $1.5 \mathrm{~mm}$ attached to a common base. Each shaft has a crosssectional area of $250 \times 250 \mu \mathrm{m}^{2}$, includes a microfluidic channel, and features four planar electrodes with a diameter of $20 \mu \mathrm{m}$ and a pitch of $500 \mu \mathrm{m}$ located up- and downstream of the liquid outlet ports. The $4 \times 4 \mathrm{~mm}^{2}$ common base with a thickness of $400 \mu \mathrm{m}$ is used for handling as well as system integration and provides access to the electrodes and microfluidic channels. For liquid supply, tubing can be directly sleeved over the protruding rectangular connectors having outer dimensions of $400 \times 400 \mu \mathrm{m}^{2}$, lengths of $1 \mathrm{~mm}$, and in-plane inlet ports. Starting at the inlet port, the rectangular microfluidic channel narrows from $200 \times 50 \mu \mathrm{m}^{2}$ to $50 \times 50 \mu \mathrm{m}^{2}$ in the shaft and is terminated by a circular out-of-plane outlet port with a diameter of $25 \mu \mathrm{m}$. The electrodes can be accessed by $150 \times 300 \mu \mathrm{m}^{2}$ bond pads on the probe base.

Probe design B (Figure 1B) differs from probe design A by a larger common base of $6 \times 4 \mathrm{~mm}^{2}$ with circular out-of-plane inlet ports located at the bottom surface. The out-of-plane inlet ports with a 
diameter of $300 \mu \mathrm{m}$ allow reversible fluidic interfacing to the platform by using O-rings. Alternatively, they enable bonding of a fluidic packaging onto the flat surface by using adhesive.

Probe design C (Figure 1C) represents a probe comb for the assembly into the NeuroProbes floating slim-base platform [31-33]. For this purpose, the shafts are attached to a common base featuring four protruding segments with widths of $390 \mu \mathrm{m}$ and lengths of $220 / 420 \mu \mathrm{m}$ enabling to mechanically secure the comb in the platform. The common base of these probe combs has a thickness of $300 \mu \mathrm{m}$ and is $2020 \times 325 \mu \mathrm{m}^{2}$ in size. Among the 8 -mm-long shafts, the two outer shafts comprise fluidic microchannels and have a rectangular cross-sectional area of $250 \times 200 \mu \mathrm{m}^{2}$, whereas the shafts in the middle reserved exclusively for electrodes are narrowed down to $150 \times 200 \mu \mathrm{m}^{2}$. Hence, compared to probe designs $\mathrm{A}$ and $\mathrm{B}$, the shafts of design $\mathrm{C}$ are thinner. Liquid supply to the fluidic shafts is achieved by in-plane inlet ports in the two outer segments. In view of design flexibility, the comb base can be used for integrating fluidic channels to the inner shafts as well. Similar to design A, the cross sections of the microchannels narrow from $200 \times 50 \mu \mathrm{m}^{2}$ at the inlet port to $50 \times 50 \mu \mathrm{m}^{2}$ in the shafts. The channels are terminated by two in-plane outlet ports of $50 \times 50 \mu \mathrm{m}^{2}$ implemented at the shaft flanks, as illustrated with the inset in Figure 1C. In addition, each shaft features four circular electrodes with a diameter of $50 \mu \mathrm{m}$ and a pitch of $400 \mu \mathrm{m}$ as well as one triangular tip electrode. All electrodes can be accessed by contact pads on the protruding segments as detailed elsewhere [31].

Additionally, various sub-variants have been realized for each of these designs. For instance, probe variants with up to two individual microchannels per shaft and shaft thicknesses as thin as $150 \mu \mathrm{m}$ are further described in $[8,20]$.

\section{Fabrication process}

The fluidic silicon microprobes are fabricated in a two-wafer silicon direct bonding process applying standard 4-inch silicon (100) wafers, deep reactive ion etching (DRIE), wafer grinding, and thin film processing, as described in detail in [8] for designs A and B and in [20] for design C. Dependent on the specific design and the intended probe thickness, the applied processing steps and wafer thicknesses vary slightly. 
In the following, the fabrication steps are illustrated in case of probe design B using $300-\mu \mathrm{m}$-thick wafers as substrate material. The general fabrication steps are summarized in Figure 2. A two-stage DRIE process is first applied to define the fluidic channels as well as the outer shape of the probes in a first silicon wafer (Figure 2A,B), i.e. the channel wafer. Thereafter, the fluidic channels are covered by a second wafer using silicon direct bonding. This second cover wafer is then reduced in thickness from 300 to $100 \mu \mathrm{m}$ by wafer grinding (Figure 2C). Subsequently, both sides of the wafer compound are covered with silicon oxide and nitride followed by deposition and patterning of a 200/300-nm-thin gold/platinum $(\mathrm{Au} / \mathrm{Pt})$ stack to form electrodes as well as interconnecting leads and contact pads. The subsequent deposition and patterning of additional silicon oxide and nitride layers protects the tracks to the electrodes (Figure 2D). Finally, the probe geometry is further defined by DRIE from both wafer stack sides. Thereby, the rear etch realizes the out-of-plane inlet ports and additionally thins down the probe shafts to a thickness of $250 \mu \mathrm{m}$ (Figure 2E), while the front etch implements the out-of-plane outlet ports (Figure 2F).

This two-wafer bonding technology offers maximum flexibility in the design of the probe geometry as well as the microfluidic features. 


\section{Results}

\section{General microprobe characteristics}

The general properties of the fabricated microprobes were characterized as described in detail in $[8,20,35]$. This includes measurements of the insertion forces, fluidic characteristics, and electrode impedances. In case of shaft cross sections of $250 \times 250 \mu \mathrm{m}^{2}$, average insertion forces of $120 \pm 13 \mathrm{mN}$ at an insertion speed of $100 \mathrm{~mm} \mathrm{min-1} \mathrm{were} \mathrm{determined} \mathrm{in} \mathrm{an} \mathrm{agarose} \mathrm{gel/polyethylene} \mathrm{foil} \mathrm{model}$ representing the cortex and pia mater [8]. With respect to the infusion of water-based liquids, all microprobe designs require modest infusion pressures to achieve infusion rates on the order of 0.5 $3 \mu \mathrm{L} / \mathrm{min}$. For instance, probe design A requires an infusion pressure of $1 \mathrm{kPa}$ to achieve an infusion rate of $1.5 \mu \mathrm{L} \mathrm{min}{ }^{-1}$ at a temperature of $26^{\circ} \mathrm{C}$ [8]. Requiring electrical connection, the electrical impedances of the recording electrodes were determined after system assembly of the microprobes as detailed in the subsequent section.

\section{Microprobe comb assembly}

In order to apply the microprobes to in vivo experiments, a system assembly enabling connection of the microprobes to macroscale mechanical, fluidic, and electronic laboratory equipment is required. Considering this, the basic assembly shown in Figure 3 offering easy handling and robustness during operation was developed as described in [36]. In detail, the assembly provides three interfaces: (1) A robust polymer packaging which allows to conveniently mechanically clamp the system assembly during insertion, e.g. in a stereotactic frame. (2) Flexible inert tubing for fluidic connection which is easily adapted to laboratory equipment using commercially available fluidic connectors. (3) A commercial micro connector which offers pluggable electrical connections to the electrodes on the probe shafts.

During the device assembly, the silicon microprobe comb (design A, cf. Figure 1A) is first bonded to the robust polyetheretherketone (PEEK) packaging by epoxy adhesive (EPO-TEK ${ }^{\circledR}$ 353ND-4, Polytec PT GmbH, Waldbronn, Germany). The protruding fluidic connectors at the platform of the microprobe 
have a cross-sectional area of $400 \times 400 \mu \mathrm{m}^{2}$. If fluidic tubing is directly sleeved over the connectors, a tubing inner diameter (ID) of $509 \mu \mathrm{m}$ (based on equivalent circumferences) is required. This increases the dead volume of the system substantially. Therefore, medical grade heat-shrinkable tubing (Raychem MT2000, Tyco Electronics, Schaffhausen, Switzerland) is applied as an adaptor and allows to attach standard 50-cm-long polytetrafluoroethylene (PTFE) tubing having an ID of $300 \mu \mathrm{m}$ and an outer diameter (OD) of $600 \mu \mathrm{m}$. After attachment, any remaining gaps resulting from the rectangular cross section of the connector are sealed with adhesive (EPO-TEK ${ }^{\circledR}$ 353ND-T, Polytec PT GmbH, Waldbronn, Germany).

The electrical interface is realized by an electrical micro connector (CLM series, Samtec, Germering, Germany) attached to a custom-made flexible printed circuit board (FPCB, ANDUS Electronic, Berlin, Germany) by reflow soldering. The assembled FPCB is bonded to the microprobe platform as well as to the PEEK packaging by using adhesive (EPO-TEK ${ }^{\circledR}$ 353ND-T). Electrical connection between the FPCB and the bond pads on the microprobe platform is realized by wire bonding followed by protection with a glob top (EPO-TEK $\left.{ }^{\circledR} 353 \mathrm{ND}-\mathrm{T}\right)$. After assembly, the average impedance of the electrodes was measured to be $2.8 \pm 1.3 \mathrm{M} \Omega$ at $1 \mathrm{kHz}$ using the experimental setup described in [8]. However, if required, Pt-grey can be electrochemically deposited on the electrodes which reduces the average impedance to $65 \pm 20 \mathrm{k} \Omega$.

Successful operation of the assembly was verified by acute in vivo experiments with anesthetized rats [36]. For this purpose, the assembly was mounted to the holder of a stereotactic frame and connected to a conventional syringe pump. During insertion, the microprobe shafts easily penetrated the adult rat dura and no broken shafts were observed. After insertion, microinfusions could be successfully administered to a variety of brain areas. The electrode configuration of the microprobe shafts is sketched in Figure 4A. In parallel, a stainless steel skull screw placed nearby with an impedance of $350 \Omega$ was applied as a differential electrode. Using this configuration, recordings of spontaneous single neuron spikes in the cerebellum could be obtained from different electrodes as shown in Figure 4B. The impact of drug delivery on the electrophysiological activity was also assessed in a separate experiment by measuring the effects of a small infusion of lidocaine (a sodium channel blocker) on 
evoked local field potentials (LFPs) in the sensory cortex [37]. Figure 4C shows the lidocaine-induced suppression of forelimb-evoked LFPs in the rat primary somatosensory cortex. The evoked potentials show an early positive deflection (onset $\sim 10 \mathrm{~ms}$ ) with a longer latency negative deflection (onset $\sim 20 \mathrm{~ms}$ ), consistent with previous studies [38]. Following lidocaine infusion, the peak-to-trough amplitude of the forelimb potential was reduced to $27 \%$ of its original amplitude ( $260 \mu \mathrm{V}$ reduced to $70 \mu \mathrm{V})$. After 20 minutes of recovery time, the forelimb-evoked potential recovered to $65 \%(170 \mu \mathrm{V})$ of its peak-to-trough amplitude as the effects of the infused lidocaine declined.

\section{Microprobe array assembly}

A microprobe array assembly can be considered as an intermediate step between a microprobe comb assembly (2D) and a fully floating microprobe array (3D). Being not as miniaturized as a floating array, such an assembly can serve as an acute and semi-chronic research tool providing neuroscientists with the possibility for simultaneous neural recording combined with drug delivery. An image of the developed microprobe array assembly primarily designed for use with larger subjects such as nonhuman primates is shown in Figure 5 [39]. The assembly consists of a small PEEK spacer onto which two microprobe combs (design A, cf. Figure 1A) are bonded by using adhesive (EPO-TEK ${ }^{\circledR} 353$ ND4) resulting in a $3 \mathrm{D}$ microprobe array. Thereby, the spacer forms not only the basis of the array, but enables also the reversible docking of a neuronavigation positioning tool in form of a special stainless steel rod. The fluidic connections to the microprobes are realized by two-component tubing: a piece of rigid polyamide (PA) tubing is sleeved over the protruding connectors of the microprobe into which flexible polyethylene (PE) tubing is inserted and secured with EPO-TEK ${ }^{\circledR} 353$ ND-T adhesive. The tubing is terminated by the commercially available injection port (SIP22/4, Instech Laboratories Inc., Plymouth Meeting, PA, USA) shown in Figure 7C which is compatible with magnetic resonance imaging (MRI). In order to access the total of 16 recording electrodes, two highly flexible polyimide (PI) ribbon cables are used [40]. The cables are connected to the bond pads of the microprobes as well as a small PCB with an attached connector (Nanoseries, Omnetics Connector Corporation, Minneapolis, USA) by applying the Microflex technology described in detail elsewhere [41,42]. After 
cable assembly, the electrical connections are protected by silicone (MED-2000, NuSil Technology, Carpinteria, CA, USA).

The microprobe array assembly was applied to semi-chronic behavioral experiments in non-human primates [39]. Specifically, temporary inactivation of the anterior intraparietal (AIP) area by stimulating the chief inhibitory neurotransmitter gamma-aminobutyric acid (GABA) with the agonist muscimol in conjunction with grasping experiments was addressed.

In order to investigate the spread of liquid by MRI, a mixture of muscimol and the MRI-contrast agent Dotarem $^{\circledR}$ (Guerbet, Villepinte, France) was used. After priming, a device was implanted inside of a custom-built MRI-compatible PEEK recording chamber typically used for such experiments [43,44]. Following craniotomy, the cylinder was anchored on the skull by dental cement enabling permanent access to the exposed dura mater. During implantation, the microprobes were oriented towards the target region (AIP area) by using the neuronavigation system Brainsight ${ }^{\mathrm{TM}}$ (Rogue Research Inc., Montreal, Canada) and inserted directly through the dura mater. In some cases, the dura was slightly thinned before insertion. All microprobe shafts survived the insertion procedure. After a recovery period, repeated reversible inactivations of the AIP were performed by injection volumes varying between 0.5 and $4 \mu \mathrm{L}$. Anatomical MRI scans at a resolution of $0.6 \mathrm{~mm}$ isotropic after injection are shown in Figure 6. Localized injections of $1-2 \mu \mathrm{L}$ into the AIP caused a deficit in grasping with the contralateral hand which correlated well with the liquid spread shown in Figure 6A and is consistent with previous findings [45]. The deficit disappeared 24 hours after the injection which is typical for this kind of inactivation experiments. In case of larger injection volumes of $4 \mu \mathrm{L}$, the muscimol solution spread to the medial bank of the intraparietal sulcus (IPS) as shown in Figure 6B. The resulting inactivation of the medial bank caused an additional deficit in reaching, i.e. correct direction of the arm to obtain a food reward. The microprobe array assembly remained implanted over a time period of 28 days. During this time, no clogging of the fluidic channels was observed. However, in general the array assembly is not intended for longer implantation times. Due to the size of the array backbone, the probes can shift inside the recording cylinder, possibly causing lesions in the brain. 


\section{Floating microprobe array}

In case of a chronically implanted multifunctional 3D microprobe array, additional aspects need to be considered [20]: During implantation, the array has to be placed in the small space between skull and brain. However, blood pulsation and head movements cause permanent relative motions of the brain with respect to the surrounding skull. If the array is rigidly connected to the skull, the stiff and fixed array shafts can interfere with the brain motions, possibly causing tissue damage. Therefore, starting at a certain brain size, the array must be mechanically decoupled from the skull and be able to "float" on the brain surface. Considering these boundary conditions, the backbone of the array (i.e. the platform) should be as thin as possible. In addition, the connecting electrical and fluidic cables are required to be highly flexible in order to prevent any mechanical interference with the floating operation.

To address these demands, the developed floating microprobe array for neural drug delivery shown in Figure 7D relies on a slim-base platform in conjunction with an elastic microfluidic cable for liquid supply. Microprobe combs, platform, and microfluidic multilumen cable are first fabricated as individual components followed by assembly as described in detail in [20].

Fabrication of the platform is based on a two-step DRIE process combined with wafer grinding of 500- $\mu$ m-thick 8 -inch silicon (100) wafers. The resulting 300- $\mu$ m-thin platform has a footprint of $4000 \times 4000 \mu \mathrm{m}^{2}$ and offers $4 \times 4$ bays enabling the insertion of up to four individual probe combs. Liquid supply to the inserted probes is realized from the platform rear. For this purpose, the bays in the corners are implemented as through-connections.

The microfluidic cable is fabricated by replica molding and oxygen plasma bonding of two silicone films (MED-6015, NuSil Technology, Carpinteria, CA, USA). The resulting highly elastic microfluidic cable has a final thickness of only $250 \mu \mathrm{m}$ and contains four independent microfluidic channels each having a cross section of $300 \times 50 \mu \mathrm{m}^{2}$. The distal end of the microfluidic cable is terminated by a PEEK adaptor with four injection ports (SIP22/4) for fluidic supply. To infuse liquids, the injection port exemplary shown in Figure 7C is connected with a septum needle. 
During assembly, the silicone cable enabling liquid delivery to the four bays with through-connections is first attached to the platform rear side by oxygen plasma bonding. Then, the protruding segments of the individual fluidic probe combs (design C, cf. Figure 1C) are inserted into the platform and secured with adhesive (EPO-TEK ${ }^{\circledR}$ 301, Polytec PT GmbH, Waldbronn, Germany) as illustrated in Figure 7A. A scanning electron micrograph of the protruding segments is shown in Figure 7B.

In a laboratory setup, liquid delivery through all four fluidic shafts could be successfully demonstrated and characterized [20].

\section{Chronic drug delivery system NeuroMedicator}

In neuroscience, microinfusions of drugs directly into the central nervous system of awake animals are widely used to investigate brain functions related to behavior. However, whereas small, skull-mounted transmitters (headstages) for wireless electrophysiological recordings are already commercially available, drug delivery relies mostly on tethered liquid infusion systems with a stationary syringe pump possibly interfering with behavior. This shortfall is addressed by the NeuroMedicator $[27,28]$ combining a fluidic microprobe comb (design B, cf. Figure 1B) with a micropumping system. The NeuroMedicator illustrated in Figure $8 \mathrm{~A}$ features $2 \times 8$ discrete liquid reservoirs interconnected in a pearl-chain-like manner which can be infused on demand. With outer dimensions of $20 \times 17.5 \times 5 \mathrm{~mm}^{3}$, the device is small and lightweight enough to be placed directly on the skull of a rat. A detailed description of the device is provided elsewhere [28].

The operational concept of the NeuroMedicator is illustrated in Figure 8B. The drug liquid is stored in the reservoir plate, i.e. a plate with interconnected reservoirs sealed on one side with an elastic film. Prior to implantation, the liquid is loaded into the reservoirs through the microprobe by applying vacuum. After implantation and electrical connection, discrete $0.25 \mu \mathrm{L}$ infusions can be sequentially released. For this purpose, short heating pulses each requiring 3.375 Ws of heating energy are applied to the composite underneath an individual reservoir. The resulting irreversible expansion deforms the elastic film into the reservoir, displaces the liquid, and releases it through the microprobe directly to the neural tissue. 
The required volumetric expansion is realized by thermally expandable Expancel $^{\circledR}$ microspheres (Expancel, Sundsvall, Sweden) embedded into an elastic polydimethylsiloxane (PDMS) matrix [46]. Expancel $^{\circledR}$ microspheres are polymeric shells with a diameter of about $10 \mu \mathrm{m}$ which contain a liquid hydrocarbon. At room temperature, the hydrocarbon is volatile and needs to be stored above its vapor pressure. Heating of the microspheres softens the polymeric shell and increases further the vapor pressure. Above a critical temperature of about $80^{\circ} \mathrm{C}$, the soft shell cannot withstand the internal pressure anymore and starts to expand. Thereby, the relaxing vapor pressure propels a volumetric expansion by a factor of up to 60 [47]. When temperature is decreased again, the expanded polymeric shell solidifies and prevents shrinkage.

The reservoir plate with the microprobe comb, the microheater array with the expandable material on top, and the device housing are first fabricated and pre-assembled as individual components followed by assembly of the complete NeuroMedicator.

In case of the reservoir plate, the liquid reservoirs are milled as spherical caps into a rigid cyclo-olefin polymer (COP) plate (Zeonor 1420R, Zeon Europe GmbH, Düsseldorf, Germany) and sealed with a laser-welded thermoplastic elastomer (TPE) film (HTF 9467/44, KRAIBURG TPE GmbH \& Co. KG, Waldkraiburg, Germany). After this, the common base of a microprobe comb (design B, cf. Figure 1B) is adhesively bonded to the front side (EPO-TEK ${ }^{\circledR}$ 353ND, Polytec PT GmbH, Waldbronn, Germany). Finally, the barrier properties of the TPE film are increased by a sputtered layer of aluminum ( $\mathrm{Al})$.

The expandable material is a composite of Expancel 820 DU 40 (Expancel, Sundsvall, Sweden) and PDMS RTV615 (Momentive Performance Materials Inc., Albany, NY, USA). To be used for actuation, a 500- $\mu$ m-thick layer is deposited by spin coating and cured on top of a PCB-based microheater array. The microheater array specifically developed for this application features micromachined titanium (Ti) heaters on one side and a reflow soldered electrical micro connector (CLM series, Samtec, Germering, Germany) on the other side. 
During assembly, the microheater array with the expandable material and the reservoir plate with the attached microprobe comb are subsequently mounted into a robust poly(methyl methacrylate) (PMMA) housing and secured with adhesive (EPO-TEK ${ }^{\circledR}$ 353ND-T). A photograph of an assembled NeuroMedicator is shown in Figure 8C.

The NeuroMedicator was successfully evaluated as a tool for pharmacological manipulation of behavior in the 5-choice serial reaction time task (5-CSRTT) [28], a behavioral test of visual attention and impulsivity. During the 5-CSRTT, a rat is trained to respond to one of five stimulation lights and a correct answer is rewarded with a food pellet. A schematic drawing of the 5-CSRTT apparatus is shown in Figure 9 and described in detail elsewhere [48,49].

For evaluation, a device filled with the N-methyl-D-aspartate (NMDA) receptor antagonist 3-((R)-2Carboxypiperazin-4-yl)-propyl-1-phosphonic acid, (R)-CPP, was implanted into a rat trained to perform the 5-CSRTT. (R)-CPP infusions targeted to the ventromedial prefrontal cortex (or infralimbic cortex) are known to increase the likelihood of rats to respond impulsively [50,51], i.e. to respond before the occurrence of a light stimulus in expectation of a food reward.

The frequency of impulsive responses was characterized before and after device implantation as shown in Figure 9. Thereby, the stable base line at the first three days after implantation suggests that passive drug leakage from the probe outlets is negligible. On the eighth day, a bilateral infusion of $0.25 \mu \mathrm{L}(\mathrm{R})$-CPP targeted to the infralimbic cortices was performed. Immediately after infusion, impulsive responding was approximately three-fold higher, but recovered to control levels on the subsequent days. 


\section{Discussion}

Different approaches for intracortical drug delivery by silicon fluidic microprobes developed within the NeuroProbes project have been summarized. Although micromachined probes represent certainly the key components for such approaches, the assembly of microprobes to complete systems offering distinct interfaces is required to enable practical applicability. Whereas chronic electrophysiological recordings can be performed today with pluggable wireless headstages, drug delivery typically requires tubing and tethered arrangements which limits its application in combination with chronic electrophysiology. Considering especially future therapeutic applications of intracortical probes, remote drug delivery is of high priority. However, as discussed above, the development of fluidic interfaces presents a formidable challenge. The two-wafer bonding process developed in NeuroProbes offers not only a maximum flexibility in the microprobe geometry, but considers also possibilities for flexible fluidic interfacing. For instance, fluidic inlet and outlet ports in virtually all spatial directions can be implemented. This flexibility was exploited to realize different assemblies.

The microprobe comb assembly can be considered to be the basic assembly concept enabling easy access to the general functionalities of the microprobe, but requires permanently attached tubing. This limits its application mostly to acute experiments. On the other hand, the microprobe array assembly offers an increased flexibility as the injection ports allow the experimenter to reversibly connect and disconnect the liquid supply. However, one has to consider that insertion and backtracking of the septum needle can already cause a liquid displacement of about $1 \mu \mathrm{L}$ resulting in infusion and suction, respectively. In addition, the presently used injection port confines a dead volume of around $8 \mu \mathrm{L}$. The array assembly can be used within a standard recording chamber, but chronically implanted assemblies require a slimmer backbone. This issue was addressed by the floating microprobe array approach having a total backbone thickness of only $550 \mu \mathrm{m}$. Similar to a highly flexible electrical ribbon cable, an elastic microfluidic multilumen cable is applied to supply the array with liquid, thereby maintaining floating operation. Unfortunately, high mechanical elasticity and barrier properties are typically contradictory requirements. Therefore, diffusive species transport through the walls of the microfluidic cable during implantation needs to be considered. Regarding a reversibly connectable liquid supply, 
the same considerations as for the microprobe array assembly apply. With respect to a multifunctional array, electrodes on the microprobe combs as well as proven electrical interconnect technologies to the platform [31,32] are available. This allows not only to assemble a floating array combining drug delivery with electrophysiology, but also to integrate probe combs with additional functions, e.g. combs with CMOS-electronics for electronic depth control [52,53] or mechanical stress mapping [54].

In general, localized drug delivery into a specific brain region is challenging. In case of pressuredriven brain infusions, liquid backflows along the applied catheters and cannulas are commonly observed depending on the infusion parameters $[55,56]$. Similarly, backflows along the shafts of the developed microprobes can occur [35].

If liquid is stored in a remote drug delivery device for the entire experiment, no pluggable fluidic interfaces are required and an autonomous drug-on-demand system results. The NeuroMedicator was developed as an add-on device to be used in conjunction with a headstage in small animal research. After filling and electrical connection, individual drug doses of $0.25 \mu \mathrm{L}$ can be infused in both hemispheres of the brain. Future development directions could target wirelessly controlled drug delivery combined with electrophysiology. For this purpose, the microprobe comb of the NeuroMedicator features recording electrodes. Thereby, a modified recording and stimulation headstage could be used for both wireless control of drug delivery as well as electrophysiology.

On the basis of the presented work, further multifunctional probes and assemblies have been developed. For instance, biosensors were integrated onto probe design B and successfully characterized [21]. Thereby, a reversible packaging taking advantage of the out-of-plane inlet ports enables fluidic as well as electrical contact and reduces assembly time of the liquid-stored probes to less than two minutes. In addition, alternative fabrication sequences have been derived from the presented core processes. In this respect, a fabrication process replacing the Si cover of probe design A with a $10-\mu \mathrm{m}$-thick bonded PI film was developed. By applying this process, microfluidic neural probes with in-channel electrodes were successfully fabricated and characterized [57]. 


\section{Acknowledgements}

This work was performed in the frame of the Information Society Technologies (IST) Integrated Project NeuroProbes of the 6th Framework Program (FP6) of the European Commission (Project number IST-027017). The authors gratefully acknowledge the support from the cleanroom and machine shop facilities at HSG-IMIT, IMTEK, and IMEC. Furthermore, the authors would like to thank all staff members of the involved institutions who supported the presented work. The provision of microspheres from Expancel, Sundsvall, Sweden, TPE films from KRAIBURG TPE GmbH \& Co. KG, Waldkraiburg, Germany, and COP plates from Zeon Europe GmbH, Düsseldorf, Germany, is gratefully acknowledged. 


\section{References}

[1] Lacey G. Microelectrophoresis and pressure ejection methods. In: Martin R, editor. Neuroscience methods: a guide for advanced students. Amsterdam: Harwood Academic Publishers 1997: 80-84.

[2] Lalley PM. Microiontophoresis and pressure ejection. In: Windhorst U, Johansson H, editors. Modern techniques in neuroscience research. Berlin: Springer 1999: 193-212.

[3] Wise KD, Angell JB, Starr A. An integrated-circuit approach to extracellular microelectrodes. IEEE Trans Biomed Eng 1970; 17: 238-247.

[4] HajjHassan M, Chodavarapu V, Musallam S. NeuroMEMS: neural probe microtechnologies. Sens 2008; 8: 6704-6726.

[5] Chen J, Wise KD, Hetke JF, Bledsoe, Jr SC. A multichannel neural probe for selective chemical delivery at the cellular level. IEEE Trans Biomed Eng 1997; 44: 760-769.

[6] Paik SJ, Lee A, Koo K, et al. Localized stimulation of and recording from neural cells with fluid injectable neuronal microneedles. In: Proc 9th Int Conf on Miniaturized Systems for Chemistry and Life Sciences ( $\mu$ TAS). Boston 2005: 1178-1179.

[7] John J, Li Y, Zhang J, Loeb JA, Xu Y. Microfabrication of 3D neural probes with combined electrical and chemical interfaces. J Micromech Microeng 2011; 21: 105011 (11pp).

[8] Seidl K, Spieth S, Herwik S, et al. In-plane silicon probes for simultaneous neural recording and drug delivery. J Micromech Microeng 2010; 20: 105006 (11pp).

[9] Kobayashi R, Kanno S, Lee S, et al. Development of double-sided Si neural probe with microfluidic channels using wafer direct bonding technique. In: Proc 4th Int IEEE/EMBS Conf on Neural Engineering (NER). Antalya 2009: 96-99.

[10] Park S, Jang Y, Kim HC, Chun K. Fabrication of drug delivery system with piezoelectric micropump for neural probe. In: Proc 23rd Int Techn Conf on Circuits/Systems, Computers and Communications (ITC-CSCC). Shimonoseki City 2008: 1149-1152.

[11] Cheung KC, Djupsund K, Dan Y, Lee LP. Implantable multichannel electrode array based on SOI technology. J Microelectromech Syst 2003; 12: 179-184.

[12] Guo K, Pei W, Li X, et al. Fabrication and characterization of implantable silicon neural probe with microfluidic channels. Sci China Technol Sci 2012; 55: 1-5.

[13] Takeuchi S, Ziegler D, Yoshida Y, Mabuchi K, Suzuki T. Parylene flexible neural probes integrated with microfluidic channels. Lab Chip 2005; 5: 519-523.

[14] Pellinen DS, Moon T, Vetter RJ, Miriani R, Kipke DR. Multifunctional flexible parylene-based intracortical microelectrodes. In: Proc 27th Annu Int Conf of the IEEE-EMBS (EMBC). Shanghai 2005: 5272-5275.

[15] Ziegler D, Suzuki T, Takeuchi S. Fabrication of flexible neural probes with built-in microfluidic channels by thermal bonding of parylene. J Microelectromech Syst 2006; 15: 1477-1482.

[16] Metz S, Bertsch A, Bertrand D, Renaud P. Flexible polyimide probes with microelectrodes and embedded microfluidic channels for simultaneous drug delivery and multi-channel monitoring of bioelectric activity. Biosens Bioelectron 2004; 19: 1309-1318. 
[17] Rubehn B, Wolff SBE, Tovote P, Lüthi A, Stieglitz T. A polymer-based neural microimplant for optogenetic applications: design and first in vivo study. Lab Chip 2013; 13: 579-588.

[18] Fernández LJ, Altuna A, Tijero M, et al. Study of functional viability of SU-8-based microneedles for neural applications. J Micromech Microeng 2009; 19: 025007 (8pp).

[19] Rohatgi P, Langhals NB, Kipke DR, Patil PG. In vivo performance of a microelectrode neural probe with integrated drug delivery. Neurosurg Focus 2009; 27: E8.

[20] Spieth S, Brett O, Seidl K, et al. A floating 3D silicon microprobe array for neural drug delivery compatible with electrical recording. J Micromech Microeng 2011; 21: 125001 (16pp).

[21] Frey O, van der Wal PD, Spieth S, et al. Biosensor microprobes with integrated microfluidic channels for bi-directional neurochemical interaction. J Neural Eng 2011; 8; 066001 (9pp).

[22] Papageorgiou DP, Shore SE, Bledsoe SC, Wise KD. A shuttered neural probe with on-chip flowmeters for chronic in vivo drug delivery. J Microelectromech Syst 2006; 15: 1025-1033.

[23] Gensler H, Sheybani R, Li PY, Mann R, Meng E. An implantable MEMS micropump system for drug delivery in small animals. Biomed Microdevices 2012; 14: 483-496.

[24] Criswell HE. A simple chronic microinjection system for use with chemitrodes. Pharmacol, Biochem Behav 1977; 6: 237-238.

[25] Bozarth MA, Wise RA. Electrolytic microinfusion transducer system: an alternative method of intracranial drug application. J Neurosci Methods 1980; 2: 273-275.

[26] Ikemoto S, Sharpe LG. A head-attachable device for injecting nanoliter volumes of drug solutions into brain sites of freely moving rats. J Neurosci Methods 2001; 110: 135-140.

[27] Spieth S, Schumacher A, Kallenbach C, Messner S, Zengerle R. The NeuroMedicator - a micropump integrated with silicon microprobes for drug delivery in neural research. $\mathrm{J}$ Micromech Microeng 2012; 22: 065020 (11pp).

[28] Spieth S, Schumacher A, Holtzman T, et al. An intra-cerebral drug delivery system for freely moving animals. Biomed Microdevices 2012; 14: 799-809.

[29] Neves HP, Orban GA, Koudelka-Hep M, Ruther P. Development of multifunctional probe arrays for cerebral applications. In: Proc 3rd Int IEEE EMBS Conf on Neural Engineering. Kohala Coast 2007: 104-109.

[30] Ruther P, Aarts A, Frey O, et al. The NeuroProbes project - multifunctional probe arrays for neural recording and stimulation. Biomed Tech 2008; 53: 238-240.

[31] Aarts AAA, Neves HP, Puers RP, Hoof CV. An interconnect for out-of-plane assembled biomedical probe arrays. J Micromech Microeng 2008; 18: 064004 (7pp).

[32] Aarts AAA, Neves HP, Puers RP, Herwik S, Seidl K, Ruther P. A slim out-of-plane 3D implantable CMOS based probe array. In: Proc Smart Systems Integration. Brussels 2009: 258263.

[33] Herwik S, Kisban S, Aarts AAA, et al. Fabrication technology for silicon-based microprobe arrays used in acute and sub-chronic neural recording. J Micromech Microeng 2009; 19: 074008 (11pp).

[34] Kisban S, Holzhammer T, Herwik S, Paul O, Ruther P. Novel method for the assembly and electrical contacting of out-of-plane microstructures. In: Proc 23rd IEEE Int Conf on Micro Electro Mechanical Systems (MEMS). Hong Kong 2010: 484-487. 
[35] Spieth S, Schumacher A, van de Moosdijk S, Haeberle S, Zengerle R. Silicon microprobe systems for neural drug delivery: experimental characterization of liquid distribution. In: Magjarevic R, Dössel O, Schlegel WC, editors. Proc World Congress on Medical Physics and Biomedical Engineering. Munich 2009. IFMBE Proceedings 25/9. Berlin: Springer 2009: 158161.

[36] Spieth S, Schumacher A, Seidl K, et al. Robust microprobe systems for simultaneous neural recording and drug delivery. In: Magjarevic R, Sloten J, Verdonck P, Nyssen M, Haueisen J, editors. Proc 4th Eur Conf of the Int Federation for Medical and Biological Engineering (ECIFMBE). Antwerp 2008. IFMBE Proceedings 22. Berlin: Springer 2009: 2426-2430.

[37] Spieth S, Schumacher A, Seidl K, et al. Microprobe systems for neural recording and drug delivery. Society for Neuroscience Annual Meeting, Washington DC 2008: Program No. 863.14, 2008 Neuroscience Meeting Planner.

[38] Freeman S, Sohmer H. A comparison of forepaw and vibrissae somatosensory cortical evoked potentials in the rat. Electroencephalogr. Clin. Neurophysiol 1996; 100: 362-369.

[39] Trenkle F, Spieth S, Kisban S, et al. Robust and MRI compatible electro-fluidic microprobe systems used for behavioral neuroscience. Society for Neuroscience Annual Meeting, Chicago 2009: Program No. 664.11, 2009 Neuroscience Meeting Planner.

[40] Stieglitz T, Beutel H, Schuettler M, Meyer J. Micromachined, polyimide-based devices for flexible neural interfaces. Biomed Microdevices 2000; 2: 283-294.

[41] Meyer J-U, Stieglitz T, Scholz O, Haberer W, Beutel H. High density interconnects and flexible hybrid assemblies for active biomedical implants. IEEE Trans Adv Packag 2001; 24: 366-374.

[42] Kisban S, Herwik S, Seidl K, et al. Microprobe array with low impedance electrodes and highly flexible polyimide cables for acute neural recording. In: Proc 29th Annu Int Conf of the IEEEEMBS (EMBC). Lyon 2007: 175-178.

[43] Kisban S, Janssen P, Herwik S, Stieglitz T, Paul O, Ruther P. Hybrid microprobes for chronic implantation in the cerebral cortex. In: Proc 30th Annu Int Conf of the IEEE-EMBS (EMBC). Vancouver 2008: 2016-2019.

[44] Stieglitz T, Rubehn B, Henle C, et al. Brain-computer interfaces: an overview of the hardware to record neural signals from the cortex. In: Verhaagen J, Hol EM, Huitenga I, et al., editors. Neurotherapy: progress in restorative neuroscience and neurology. Progress in Brain Research 175. Amsterdam: Elsevier 2009: 297-315.

[45] Gallese V, Murata A, Kaseda M, Niki N, Sakata H. Deficit of hand preshaping after muscimol injection in monkey parietal cortex. Neuroreport 1994; 5: 1525-1529.

[46] Samel B, Griss P, Stemme G. A thermally responsive PDMS composite and its microfluidic applications. J Microelectromech Syst 2007; 16: 50-57.

[47] Expancel, Sundsvall, Sweden. Eine technische Präsentation der Expancel Mikrosphären. Technische Information Nr. 40. Issue 2006-07-24.

[48] Robbins TW. The 5-choice serial reaction time task: behavioural pharmacology and functional neurochemistry. Psychopharmacology (Heidelberg, Ger) 2002; 163: 362-380.

[49] Bari A, Dalley JW, Robbins TW. The application of the 5-choice serial reaction time task for the assessment of visual attentional processes and impulse control in rats. Nature Protocols 2008; 3 : 759-767. 
[50] Murphy ER, Dalley JW, Robbins TW. Local glutamate receptor antagonism in the rat prefrontal cortex disrupts response inhibition in a visuospatial attentional task. Psychopharmacology (Heidelberg, Ger) 2005; 179: 99-107.

[51] Carli M, Baviera M, Invernizzi RW, Balducci C. Dissociable contribution of 5-HT1A and 5HT2A receptors in the medial prefrontal cortex to different aspects of executive control such as impulsivity and compulsive perseveration in rats. Neuropsychopharmacology 2006; 31: 757767.

[52] Seidl K, Herwik S, Torfs T, Neves HP, Paul O, Ruther P. CMOS-based high-density silicon microprobe arrays for electronic depth control in intracortical neural recording. J Microelectromech Syst 2011; 20: 1439-1448.

[53] Torfs T, Aarts AAA, Erismis MA, et al. Two-dimensional multi-channel neural probes with electronic depth control. IEEE Trans Biomed Circuits Syst 2011; 5: 403-412.

[54] Seidl K, Lemke B, Ramirez H, Herwik S, Ruther P, Paul O. CMOS-based high-density silicon microprobe for stress mapping in intracortical applications. In: Proc 23rd IEEE Int Conf on Micro Electro Mechanical Systems (MEMS). Hong Kong 2010: 35-38.

[55] Chen MY, Lonser RR, Morrison PF, Governale LS, Oldfield EH. Variables affecting convection-enhanced delivery to the striatum: a systematic examination of rate of infusion, cannula size, infusate concentration, and tissue-cannula sealing time. J Neurosurg 1999; 90: $315-320$.

[56] Morrison PF, Chen MY, Chadwick RS, Lonser RR, Oldfield EH. Focal delivery during direct infusion to brain: role of flow rate, catheter diameter, and tissue mechanics. Am J Physiol-Reg I 1999; 277: R1218-R1229.

[57] Moser D, Seidl K, Paul O, Ruther P. Fabrication of microfluidic neural probes with inchannel electrodes. In: Proc IEEE Sensors 2012. Taipei 2012: 1-4. 


\section{Figure legends}

Figure 1 Fluidic silicon microprobe designs: Design A and B offer a common probe base with in- and out-of-plane inlet ports, respectively, as well as out-of-plane outlet ports. Design C features in-plane outlet ports while the common base offers protruding segments with integrated in-plane inlet ports for assembly into a floating platform.

Figure 2 General fabrication steps of the silicon microprobes: (A),(B) two-stage DRIE process to implement the channel structure and probe shape, (C) direct wafer-to-wafer bonding and grinding, (D) deposition and patterning of electrodes, $(\mathrm{E})$ rear and $(\mathrm{F})$ front side oxide patterning followed by DRIE for probe patterning.

Figure 3 Microprobe comb assembly with attached PTFE-tubing and micro connector serving as fluidic and electrical interfaces, respectively, in comparison to a one Euro-Cent-coin.

Figure 4 Results of acute experiments: (A) Electrode configuration of the microprobe shafts; (B) spontaneous single neuron spikes in cerebellum (raw data and superimposed spike waveforms); (C) lidocaine-induced inactivation of forelimb-evoked LFPs in the rat primary somatosensory cortex after delivery of $0.4 \mu \mathrm{L}$ of a $5 \%$ lidocaine solution. The data shown are averages of five stimuli. The LFPs were recorded with electrode no. 6 next to the liquid outlet port.

Figure 5 Microprobe array assembly with $2 \times 2$ probe shafts offering an electrical micro connector, dockings for injection ports, and a guidance for a positioning tool.

Figure 6 MRI scans after injection of (A) $2 \mu \mathrm{L}$ of a Muscimol/Dotarem ${ }^{\circledR}$ mixture in a non-human primate's AIP and (B) additional liquid spread to the medial bank of the IPS after injection of $4 \mu \mathrm{L}$.

Figure 7 Floating microprobe array: (A) illustration of the comb assembly into the floating platform; (B) scanning electron micrograph of a probe comb with electrodes; (C) injection port with septum needle; (D) image of an assembled array with inserted combs (without electrodes).

Figure 8 Drug delivery system NeuroMedicator: (A) Illustration of the device concept; (B) principle of operation based on (1) individual liquid reservoirs sealed on one side with an elastic film, (2) filling with liquid in vacuum, and (3),(4) localized heating of the expandable material displacing discrete liquid amounts; (C) photograph of an assembled NeuroMedicator.

Figure 9 Percentage of impulsive responses during the 5-CSRTT before and after infusion of (R)-CPP into the rat mPFC. The NeuroMedicator was implanted on the fourth day. 
Figure 1

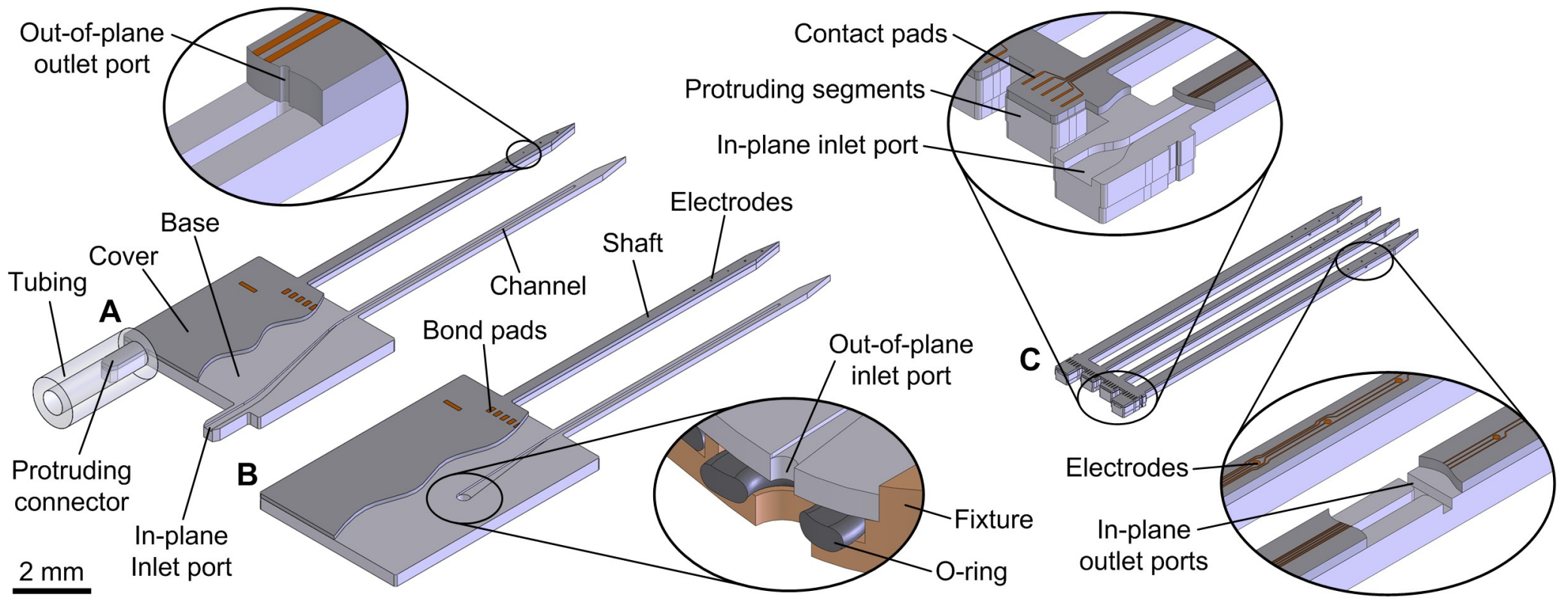


Figure 2

A

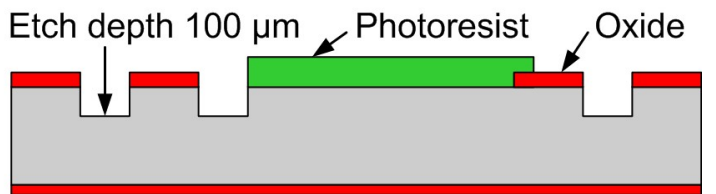

Etch depth $150 \mu \mathrm{m} \quad$ Etch depth $50 \mu \mathrm{m}$

B

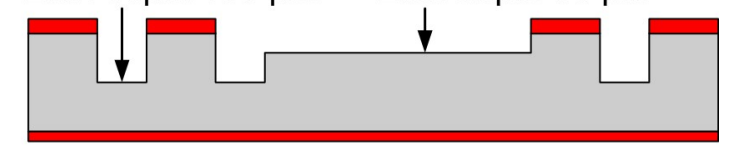

C

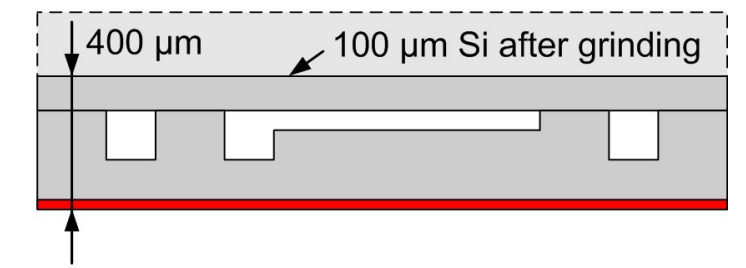

Bond pad Electrode

D

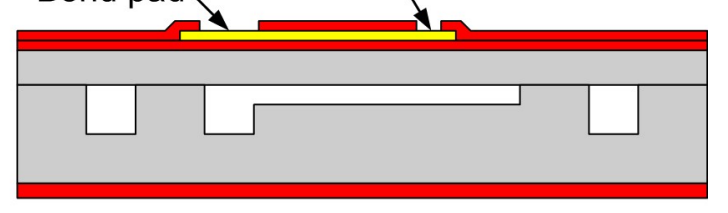

E

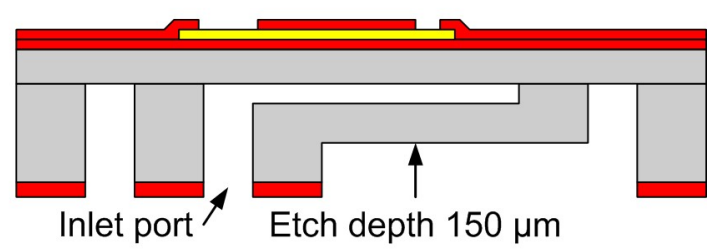

Etch depth $100 \mu \mathrm{m}$

Outlet port

F

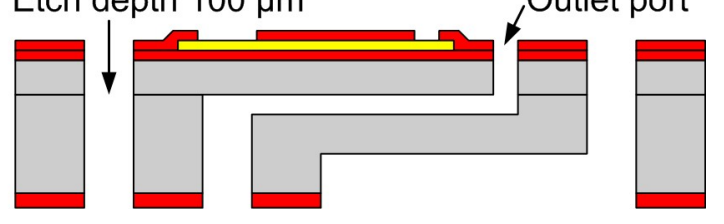




\section{Figure 3}

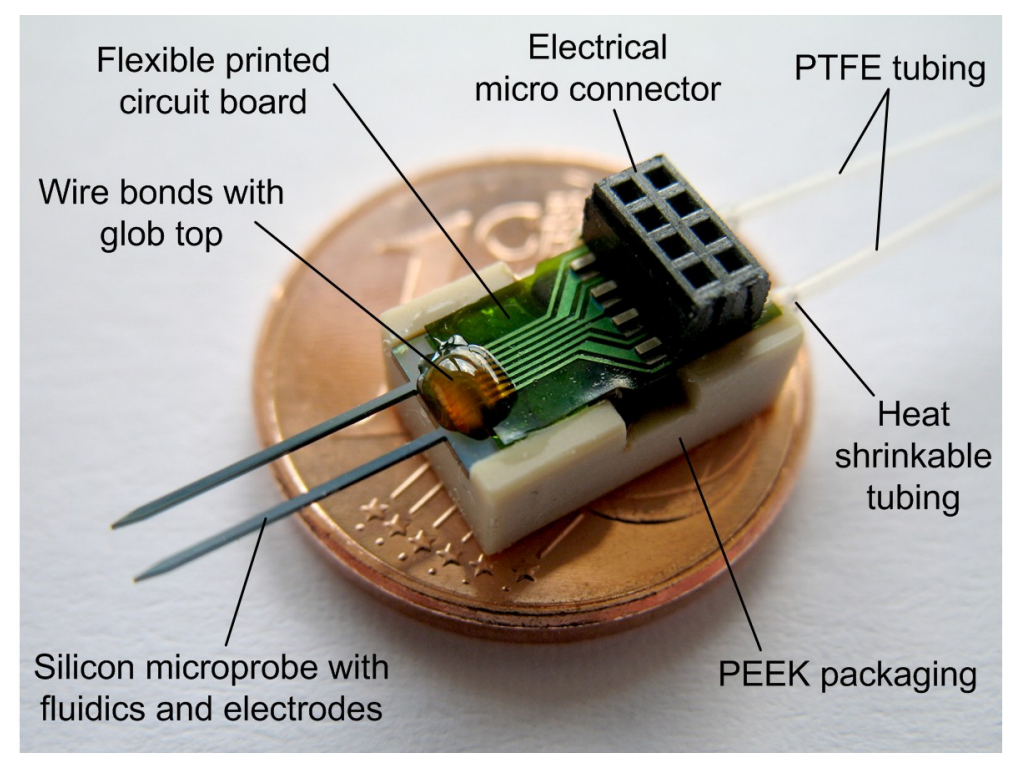


Figure 4

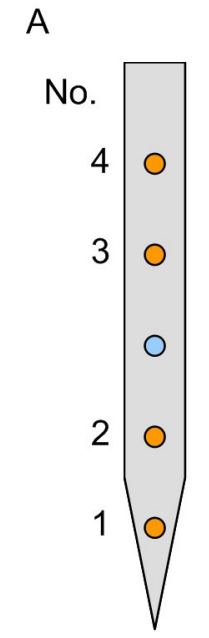

B
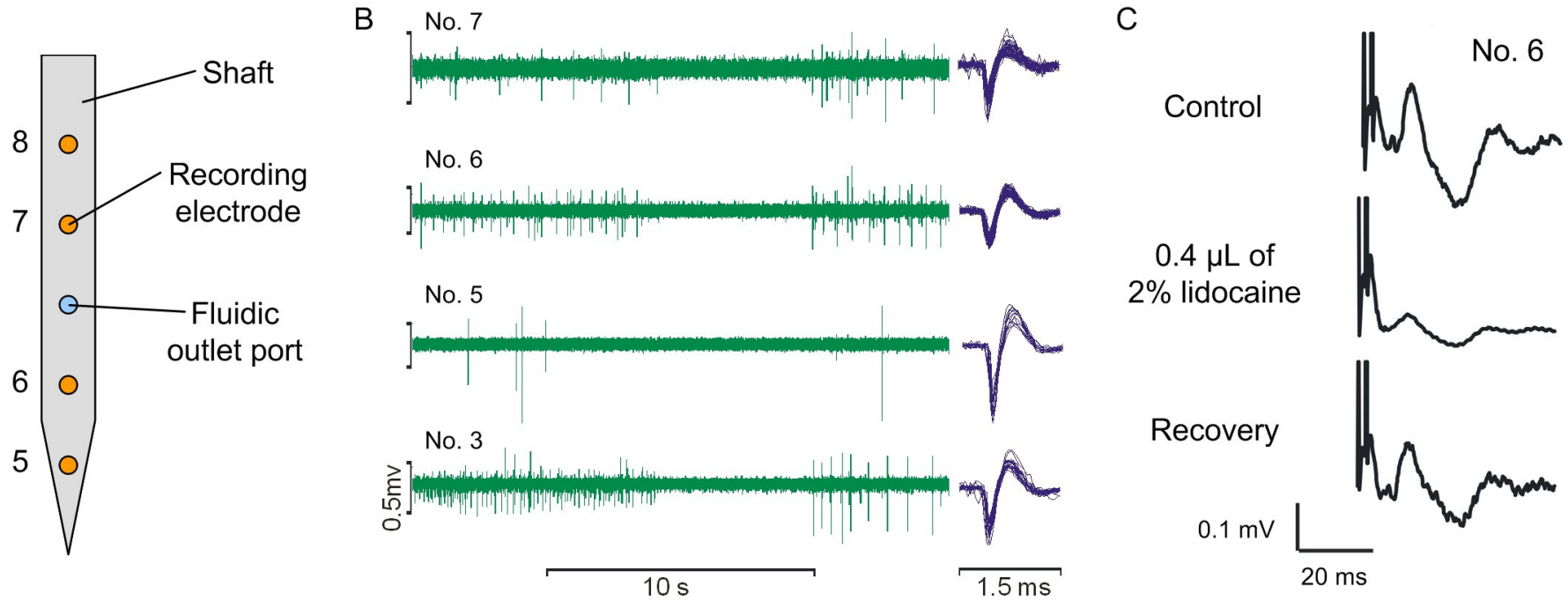


\section{Figure 5}

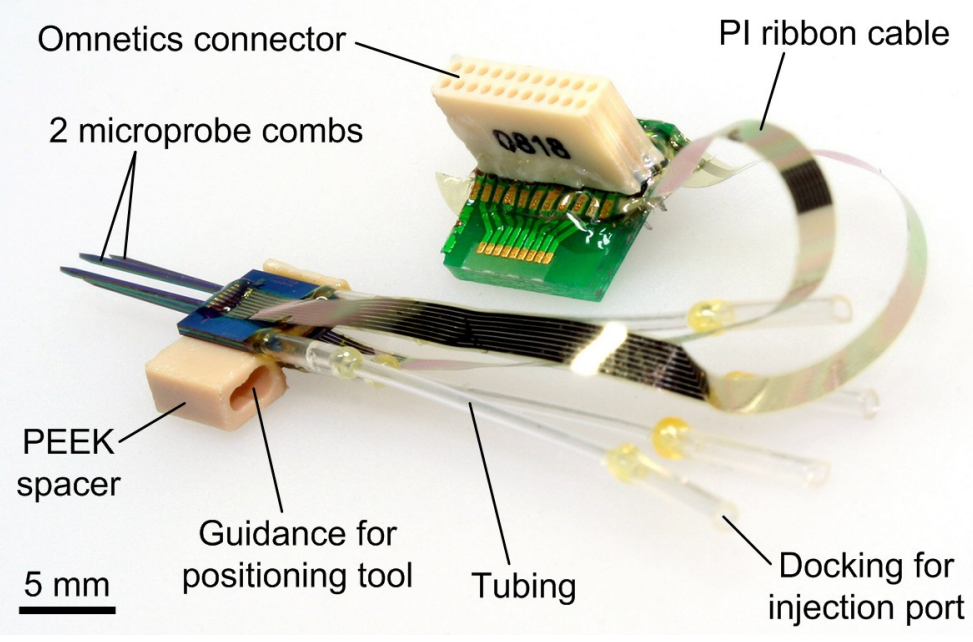




\section{Figure 6}

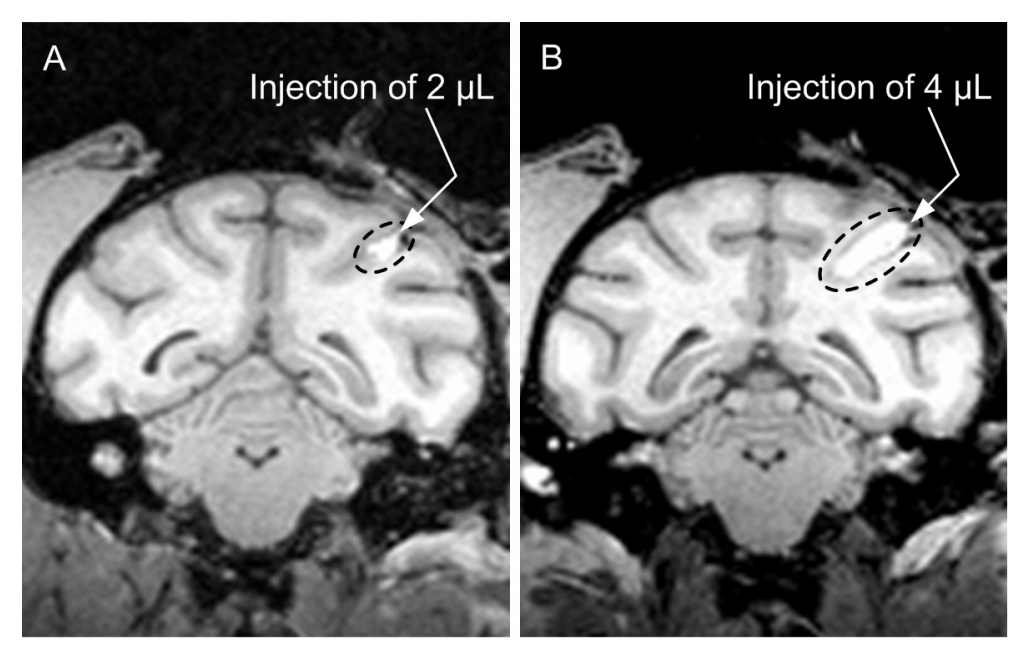




\section{Figure 7}
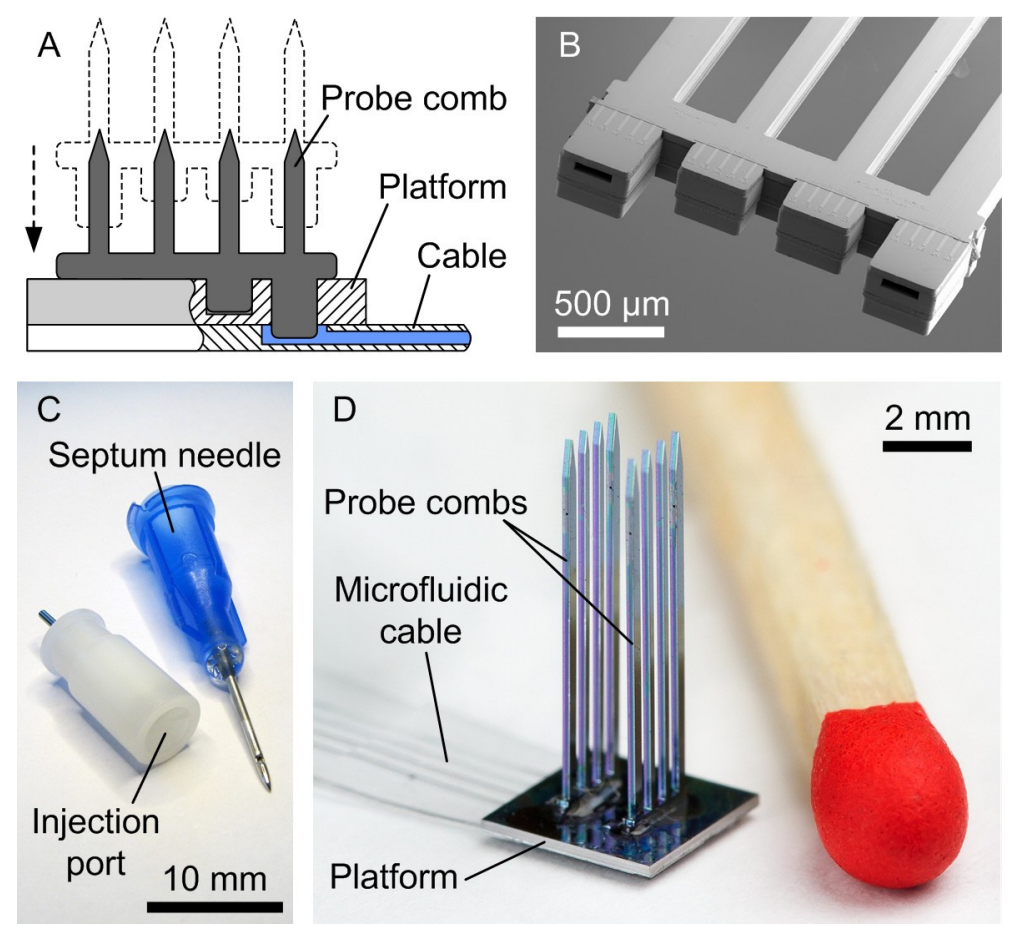

$2 \mathrm{~mm}$ 
Figure 8

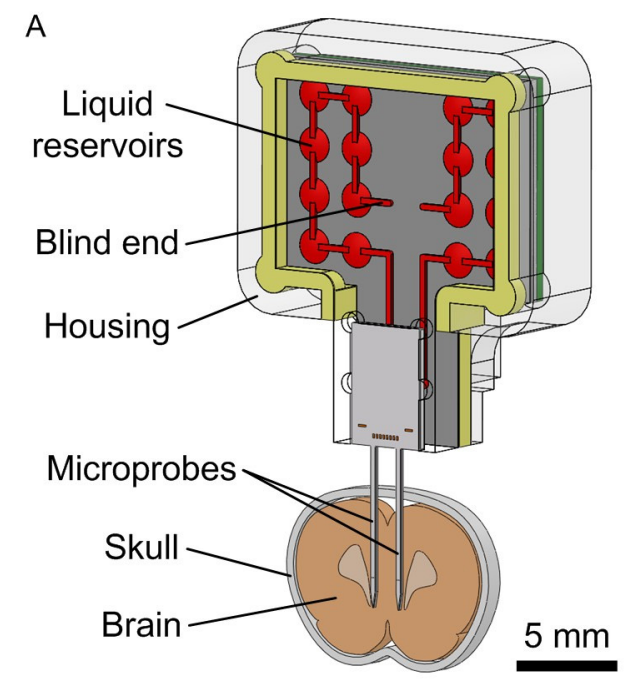

B

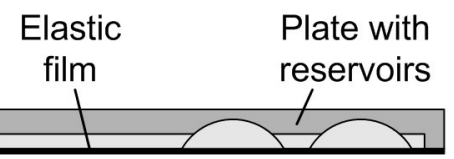

(1)

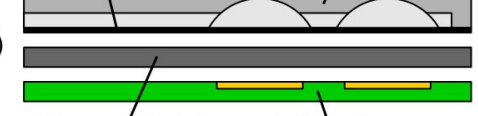

Expandable Microheater

material array

(2)

Liquid

(3)

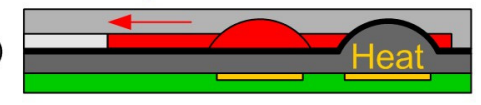

(4)
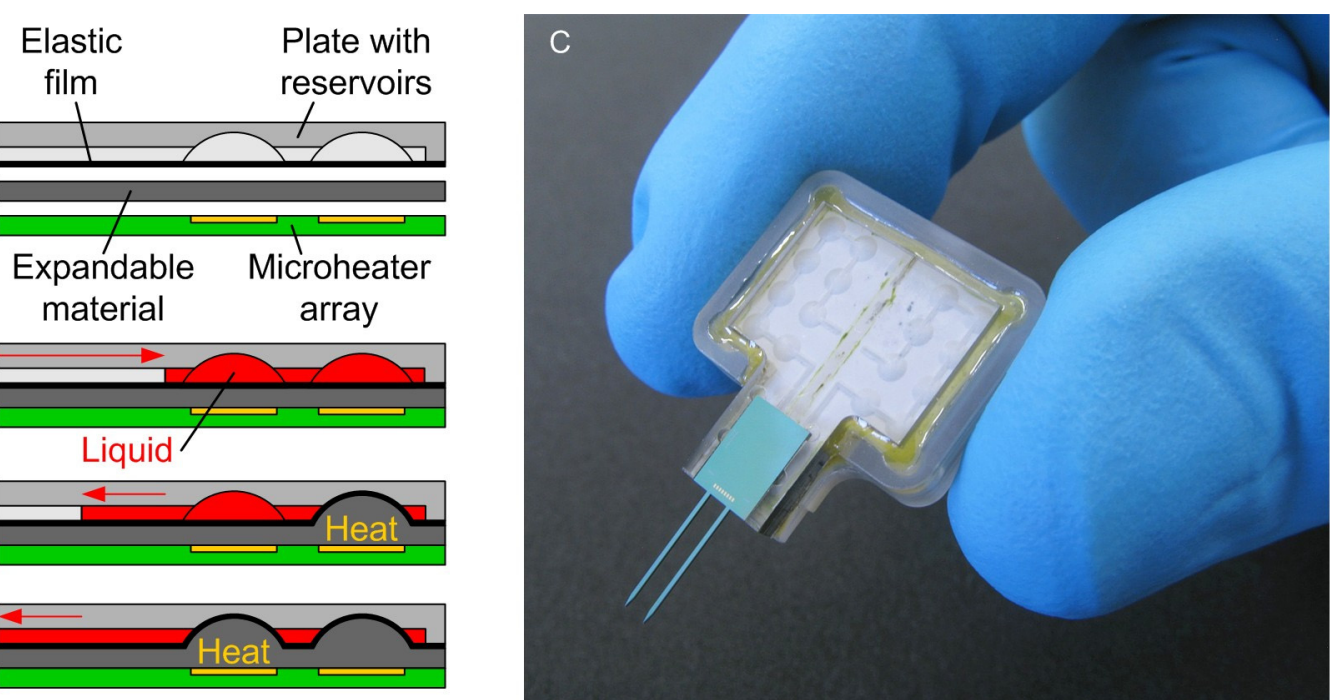
Figure 9

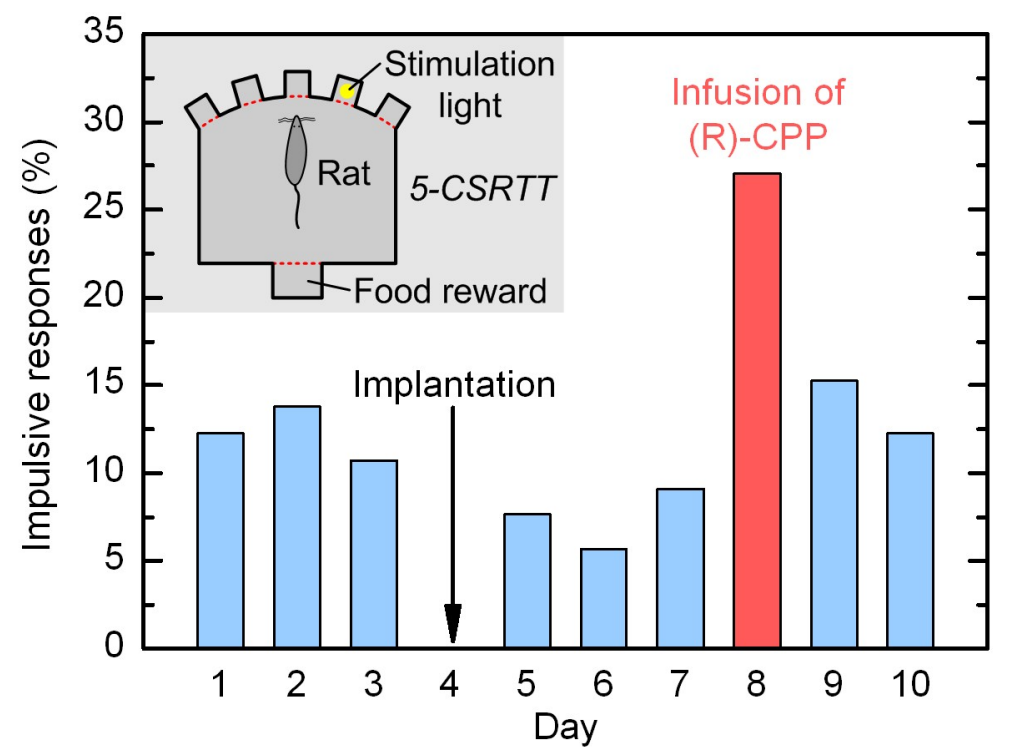

